\title{
A gestão pedagógica da escola e as concepções de um programa do Instituto Ayrton Senna: de qual pedagógico falamos?
}

\author{
Maria Raquel Caetano ${ }^{1}$
}

\section{Resumo}

Este artigo analisa as concepções pedagógicas do Instituto Ayrton Senna na educação e as implicações decorrentes da implantação do Programa Circuito Campeão na gestão pedagógica da escola e da sala de aula. A concepção pedagógica de um sistema e de uma escola está diretamente relacionada ao projeto político-pedagógico de ambos. Os programas do Instituto Ayrton Senna (IAS) vêm sendo implantados nas redes públicas do país, sendo referendados e financiados pelo Ministério da Educação através do Guia de Tecnologias Educacionais. O IAS tem apresentado que seus programas podem ser desenvolvidos independentemente da concepção de educação e do método de trabalho, ou seja, os programas podem ser utilizados nas escolas de todo o Brasil, pois trabalham com o foco do gerenciamento. Nesse sentido, apresentaremos as concepções utilizadas pelo Programa Circuito Campeão, os conceitos com que trabalha, buscando evidenciar, dessa forma, os referenciais da gestão pedagógica desse programa e do IAS.

Palavras-chave: Gestão Pedagógica. Escola. Programa Circuito Campeão.

\begin{abstract}
This paper explores pedagogical conceptions of Instituto Ayrton Senna in education and the implications of the implementation of the Circuit Champion in the pedagogical management of the school and the classroom. The pedagogical design of a system and of a school is directly related to the political-pedagogical project of both. The programs of the Institute Ayrton Senna (IAS) are being deployed in public networks of the country, being countersigneds and financed by the Ministry of Education through the Educational Technology Guide. The IAS has shown that its programs can be developed independently of the conception of education and of the method of work, ie, this programs can be used in schools from all over Brazil, because they work with the focus of management. In this direction, we present the conceptions used by the Circuit Champion, the concepts which works, seeking to evidence thus the references of the pedagogical management of this program and the IAS.
\end{abstract}

Keywords: Educational Management. School. Circuit Champion Program.

\footnotetext{
${ }^{1}$ Doutora em Educação. Professora das Faculdades Integradas de Taquara - Faccat/RS. rcaetano@faccat.br.
} 


\section{A gestão pedagógica da escola}

A escola, como campo privilegiado de intervenções política e ideológica, traz na sua essência pedagógica a possibilidade de construção de novas práticas que priorizem a via democrática escolar e na sociedade. Pressupõe-se, assim, autonomia para que cada escola possa construir seu projeto político-pedagógico e estabelecer seu próprio sistema de avaliação.

Nesse sentido, a escola torna-se democrática, e sua essência pedagógica é traduzida por seu caráter público, pelas novas relações sociais que estabelece, pela democratização das decisões e formação da cidadania. A gestão da escola deve estar pautada no seu projeto político-pedagógico, pois este implica a participação da comunidade escolar na definição de suas políticas e seus projetos educacionais. A escola não é democrática só por sua prática administrativa. Ela se torna democrática por toda a sua ação pedagógica essencialmente educativa.

Entendemos que, para que o processo educativo se efetive, são necessários uma teoria e um conjunto de objetivos e meios formativos, encaminhados à formação humana. As atividades educativas ocorrem em determinadas condições históricas e sociais que estabelecem limites às possibilidades objetivas da humanização (LIBÂNEO, 2002, p. 142). As finalidades e meios da educação subordinam-se à estrutura e à dinâmica das relações entre classes e grupos sociais, e a prática assume os interesses de determinados grupos.

Para Libâneo (2002), o pedagógico, nesse sentido, é a intenção, a sistematização a orientação da prática, de modo consciente, para exercer finalidades sociais e políticas cunhadas, a partir de interesses concretos, no seio da práxis social. Segundo o autor, o que define um conceito, uma ação, uma prática como pedagógica é a direção de sentido que se dá às práticas educativas. "É o caráter pedagógico que faz distinguir os processos educativos que se manifestam em situações sociais concretas, uma vez que é a análise pedagógica que explicita a orientação, a direção da atividade educativa numa visão emancipadora dos sujeitos" (LIBÂNEO, 2002 p. 143).

O Instituto Ayrton Senna (2008), denominado nesse texto de IAS, vem sendo implantado nas redes públicas do país, sendo referendado e financiado pelo Ministério da Educação através do Guia de Tecnologias Educacionais. O IAS tem 
apresentado que seus programas podem ser desenvolvidos independentemente da concepção de educação e método de trabalho, ou seja, os programas podem ser utilizados por escolas de todo o Brasil, pois trabalham com o foco do gerenciamento. Nesse sentido, serão apresentadas, neste estudo, as concepções utilizadas pelo Programa Circuito Campeão em um sistema municipal de educação, no estado do Rio Grande do Sul, os conceitos com que trabalha, visando mostrar, assim, a gestão pedagógica desse programa e do IAS.

Para juntar esse quebra-cabeça, iniciamos tratando de alguns conceitos mais gerais para entender a filosofia do programa e suas concepções, que não são neutras. Existem concepções em disputa, e, nesse sentido, o IAS se articula com o setor público e privado com o objetivo de imprimir "sua" lógica educacional na educação brasileira.

A concepção pedagógica de um sistema e de uma escola está diretamente relacionada com o projeto político-pedagógico de ambos. A partir do momento em que um programa não estatal, mas financiado com dinheiro público, passa a fazer parte da rotina das escolas e das salas de aula, com um rígido controle de cima para baixo, o sistema e a escola passam a incorporar as ações do programa, apresentando ou não resistências, dependendo da forma como este é implantado. Tendo em vista essas ideias, passamos a trabalhar com os conceitos que adentram nos sistemas públicos, através das secretarias de educação, principalmente nas escolas.

Iniciaremos abordando o projeto político-pedagógico da escola que, para o Programa Circuito Campeão, é apenas projeto pedagógico, ou seja, o político está desvinculado do projeto, porque não está articulado aos interesses reais e coletivos da população, como afirmam Veiga e Resende (1996). Se o político está relacionado com o compromisso na formação do cidadão, para um determinado tipo de sociedade, embora o IAS tenha explicitamente esse objetivo, a questão do político inexiste.

A educação e a escola não são consideradas neutras, estando, necessariamente, articuladas a uma concepção particular de mundo e de sociedade. Não se trata, portanto, de associar ou não a educação escolar com a política: essa associação já está implícita na ação da escola, que, "longe de ser universal, numa sociedade de classes, atende aos interesses dos grupos dominantes que, por meio dela, incutem a concepção de mundo e de homem que lhes é mais favorável" (PARO, 2002, p. 13). 
Concordando com o autor, defendemos a necessária ligação entre política e educação escolar, ou seja, uma visão da política que se identifica com a luta entre grupos portadores de interesses divergentes na sociedade, pois não se trata de uma "atividade que deva estar presa aos limites do Estado, do partido político ou do poder legislativo, nem se constitui em algo menos digno que não possa estar associado com a prática pedagógica escolar" (PARO, 2002). Pelo contrário, para Paro (2002), trata-se de usar a própria educação como instrumento de ação política, porque isso contribui para tirar a educação da posição acrítica de uma neutralidade política que, de fato, não é positiva para os fins da democracia na escola.

Em se tratando de relações sociais, não é possível alcançar fins promotores da democracia e da afirmação de sujeitos históricos a partir da utilização de meios que não sejam democráticos (PARO, 2002). No caso da escola, "se estamos preocupados com fins educativos, ou seja, de constituição de sujeitos históricos, a forma de atingi-los deve ser, necessariamente, adequada com esses fins, o que exige uma gestão escolar democrática". (PARO, 2002, p. 17).

Tendo em vista que a gestão democrática como um princípio consagrado pela Constituição vigente abrange as dimensões pedagógica, administrativa e financeira, sua dimensão pedagógica reside na possibilidade de efetivação da intencionalidade da escola, que é a formação do cidadão participativo, responsável, compromissado, crítico e criativo. Depreende-se daí a importância da participação e, conforme Veiga (2004), a possibilidade da construção do projeto político-pedagógico passa pela relativa autonomia da escola e da capacidade que tem de delinear sua própria identidade na construção do projeto político-pedagógico. "O projeto-político pedagógico não visa apenas a um rearranjo formal da escola, mas a uma qualidade em todo processo vivido" (VEIGA, 2004, p. 14).

O projeto político-pedagógico exige uma reflexão acerca da concepção de educação e sua relação com a sociedade e a escola, o que não deixa de lado uma reflexão sobre o homem a ser formado e as questões vinculadas à cidadania, ao trabalho e à consciência crítica. Com base nas reflexões anunciadas, cabe à escola explicitar os fundamentos teórico-metodológicos, os objetivos, os conteúdos, a metodologia da aprendizagem, o tipo de organização e as formas de execução e avaliação da escola. O IAS apresenta que o Programa Circuito Campeão pode ser desenvolvido independente da concepção de educação e da proposta pedagógica 
do sistema ou da escola. O programa pode ser utilizado em todo o Brasil, independentemente da região, município ou estado. Pode atender a uma aldeia indígena ou imigrantes da região sul do Brasil, bem como o sertão nordestino ou a floresta amazônica, descaracterizando, dessa forma, os sujeitos, professores e alunos que estão na escola pública.

Tendo em vista essas questões, investigamos, em documentos, notícias e sites, alguns vestígios que abordassem as teorias que fundamentam a proposta do IAS ou mais especificamente do Programa Circuito Campeão. Encontramos algumas informações na dissertação de mestrado de Eduardo Malini, que investigou o Plano de Desenvolvimento da Educação. Em entrevista a Malini (2009), a secretária executiva do IAS à época, Margareth Goldenberg, cita a visão autônoma que o IAS adota em relação a essa questão:

Não dever satisfação a sindicato nenhum, à academia nenhuma, à
universidade nenhuma é muito bom. Então nós estamos sempre abertos a
diálogos e negociações, mas a única forma que a gente discute é
mostrando resultados. A gente não entra nessas discussões filosóficas e
acadêmicas. A gente não tem tempo para isso [...] Então quando a
discussão fica muito filosófica e processual, indicando autores, 'Ah! Que
Piaget achava isso, que Vygotsky achava aquilo' [...]. nós saímos fora.
Primeiro porque nós não temos uma linha declarada, não temos uma linha
metodológica porque seria ruim. Como é que eu trabalho no Brasil seguindo
uma linha metodológica [...] Construtivista? Não daria. Nós não temos isso
claramente (GOLDBERG apud MALINI, 2009, p. 123).

A fala de Goldenberg nos remete a pensar que a concepção que o IAS adota é de uma educação neutra e científica, cujos métodos são técnicas que devem garantir apenas resultados. "Encontra-se aqui, portanto um viés educacional que busca desarticular política e educação para em consequência desarticular uma consciência política nela, sobre ela e a partir dela. Essa concepção invariavelmente procura ver a escola de forma linear e não contraditória" (EVANGELISTA, 2007, p. 34). No sentido de pensar esse caráter contraditório da escola, recorremos a Cury quando afirma que

os agentes pedagógicos representam os divulgadores mais imediatos da concepção de mundo que busca o consentimento ativo e coletivo das classes sociais, em função do projeto hegemônico existente. Ao atuarem nesse nível, tornam-se mediadores, para as consciências, das realidades sociais que defendem e divulgam (CURY, 1992, p. 113).

Essa forma de compreender a escola elucida, de modo mais objetivo, seu caráter contraditório, demonstrando que, se de um lado, no seu interior, é veiculado 
um conteúdo que busca o consentimento dos educandos e educadores para um projeto dominante, de outro lado, é possível difundir um conhecimento que dê conta de compreender esse projeto, articulando, ao mesmo tempo, um projeto próprio dos dominados (EVANGELISTA, 2007). Concordamos com a autora, quando ela afirma que os agentes pedagógicos agem no âmbito da hegemonia, divulgando e consolidando, principalmente, a concepção de mundo própria da burguesia; não se pode afirmar, entretanto, que esse processo conte com sua atuação consciente. Por outro lado, "a percepção destes movimentos no interior da escola (reprodução das relações sociais vigentes e articulação de uma concepção contrária a essa reprodução) nos instiga a pensar que a escola não possui superpoderes, nem é impotente diante da realidade" (EVANGELISTA, 2007, p. 35).

Embora o IAS não apresente explicitamente uma concepção pedagógica, para Miskalo (2009), é preciso que todos os envolvidos compartilhem os mesmos ideais, tenham a mesma compreensão, entendam as ações estratégicas e, por fim, sejam competentes para desempenhar a sua função. O centro desse processo sempre é o aluno, e a gestão deve pautar-se por alinhamentos espirituais ou essenciais, conceituais, estratégicos e operacionais.

Para ela, a responsabilidade pelo sucesso do aluno está nas mãos das equipes das escolas e da Secretaria de Educação, que devem manter-se permanentemente articuladas. Machado (1994), fazendo uma análise dos modelos gerenciais cartesianos, afirma que todos devem atuar conscientemente e assumir as responsabilidades pelos resultados do processo.

Miskalo (2009) apresenta o que, segundo ela, é o alinhamento da gestão educacional para o sucesso no programa, norteada por três eixos:

- pedagógico, significando a sistematização dos atos de aprender e ensinar.

- político, que envolve o "desejo" do governador ou do prefeito;

- gerencial, que envolve o acompanhamento sistemático do processo e dos resultados.

Para os autores que defendem esse modelo de gestão, a suposta participação de todos é necessária para que a metodologia gerencial funcione bem. O estabelecimento do ideal comum e do alinhamento é a própria filosofia do programa, pois passa a ser traduzido em planos acessíveis, capazes de serem desdobrados em 
ações para o dia a dia. A insistência no esforço do alinhamento é fazer com que as pessoas sejam despertadas e conscientizadas para o foco do trabalho.

Machado (1994, p. 46) complementa que, havendo motivação, elas sentirão vontade de aderir e aprender a atuar ofensivamente para essa missão. Para o IAS, o controle constitui-se o verdadeiro fio condutor desse sistema, pois, assim, assegurarse-á a implantação do programa, desde a "alta gerência" (governador, prefeito) até a sala de aula, no caso, professores e alunos, cada qual com suas metas a cumprir.

Defensor da gestão gerencial, materializada pela gestão da qualidade total, nos anos 90, Antonio Carlos R. Xavier ${ }^{2}$ (1996, p. 13) sustenta o comprometimento da liderança. Nesse caso, o prefeito, o governador ou mesmo o secretário de educação são condição sine qua non para o sucesso de um programa, pois a gestão da qualidade começa pelos escalões mais altos da organização. Esse processo pode ser considerado top-down, por se realizar de cima para baixo, sendo o prefeito e o governador sujeitos principais. Há uma identificação com o nível hierárquico e a liderança, pois essa é a forma de garantir o desenvolvimento do programa, principalmente através do controle dos sujeitos.

O IAS trabalha com o conceito de sucesso quando acompanha os indicadores relacionados ao trabalho do professor e do aluno. Nesse caso, o sucesso ocorre quando os alunos demonstram, através dos indicadores propostos, que houve avanço em relação à aprendizagem e quando o professor desenvolveu o que estava proposto nos próprios manuais, ou seja, planejou as aulas conforme o estabelecido no fluxo, participou das reuniões com o coordenador e coletou a frequência do aluno.

Para compreendermos o que o programa apresenta por gestão do ensino, é necessário buscar os conceitos que estão, muitas vezes, subjacentes nos documentos apresentados pelo Programa Circuito Campeão. Esses conceitos que apresentaremos integram, a nosso ver, o currículo, como "organização do conjunto das atividades nucleares distribuídas no tempo e no espaço. Um currículo é a escola desempenhando a função que lhe é própria: o saber escolar" (SAVIANI, 2010, p. 18).

O Quadro 1 mostra o entendimento da gestão do ensino que está ligado diretamente ao trabalho do professor em sala de aula.

\footnotetext{
${ }^{2}$ Foi diretor de políticas públicas do IPEA na gestão de FHC.
} 


\section{Quadro 1 - Gestão do Ensino do IAS - Circuito Campeão.}

\begin{tabular}{|c|}
\hline GESTÃO DO ENSINO \\
\hline Planejamento de ações para: \\
\hline Assegurar a frequência dos alunos e a realização da lição de casa; \\
\hline Provocar avanços na aprendizagem em geral; \\
\hline Organizar os espaços, tempos e tarefas; \\
\hline Assegurar a média de livros lidos por mês; \\
\hline Assegurar a boa gestão de sua classe; \\
\hline Atender ao previsto no fluxo das aulas; \\
\hline Assegurar 95\% de promoção; \\
\hline Assegurar 95\% de alfabetização de alunos na 1ª série; \\
\hline Adotar e cumprir uma rotina diária de aulas; \\
\hline Ouvir e aconselhar familiares; \\
\hline Melhorar relacionamentos dos alunos entre si e com o professor; \\
\hline Melhorar a autoestima dos alunos; \\
\hline Fortalecer sua formação pedagógica. \\
\hline
\end{tabular}

Fonte: Apresentação do IAS na capacitação de professores em 2009.

Entendemos, também, que o currículo não é neutro, mas condicionado pelas hierarquias sociais, raciais, de classe ou gênero. É, segundo Arroyo (2007, p. 19), "a matéria-prima com que a escola desenvolve sua concepção de currículo". Nessa perspectiva, para o autor, organizar a escola, os tempos e os conhecimentos, o que ensinar e aprender, respeitando a especificidade de cada tempo de formação dos alunos, não é uma opção a mais nas formas de organização escolar e curricular. "É uma exigência do direito que os educandos têm a ser respeitados em seus tempos mentais, culturais, éticos, humanos" (ARROYO, 2007, p. 46). Nesses termos, apresentaremos os conceitos que integram o currículo através das concepções do Programa Circuito Campeão.

O planejamento do professor deve assegurar os 200 dias de efetivo trabalho, em sala de aula, com os alunos, e ser realizado utilizando a matriz de habilidades e competências com o objetivo de assegurar 95\% de alfabetização na sua turma e 95\% de promoção, no caso das primeiras séries. Para o Circuito Campeão, os profissionais da educação precisam, também, lançar mão de recursos que garantam o sucesso de seus alunos e, logicamente, o seu próprio, como o Plano de Ensino ou de Trabalho, a ser desenvolvido, paulatinamente, durante os 200 dias/800 horas 
mínimas que compõem o calendário escolar. Destacam-se dois conceitos para o planejamento: Matrizes de Habilidades e Fluxo das Aulas.

As habilidades no Circuito Campeão devem estar distribuídas no Fluxo das Aulas, que é o plano que o professor faz, trazendo para a sala de aula a visão de educação, os indicadores de qualidade e as metas de desenvolvimento construídas a partir das diretrizes definidas para a rede de ensino. Esse plano, baseado nas Matrizes de Habilidades, é a ferramenta de trabalho do professor, ao qual deve, sistematicamente, recorrer, para avaliar se a execução está compatível com o proposto, ou se ajustes serão necessários.

Assim, o Fluxo das Aulas dos primeiros anos iniciais do Ensino Fundamental deve ser proposto pela Secretaria de Educação, adequado pela equipe escolar e adotado pelos docentes, considerados o calendário escolar, a realidade dos alunos e a Proposta Pedagógica da Unidade. Segundo o IAS, esse Fluxo deve garantir eficácia e eficiência ao processo de alfabetização e permitir à equipe responsável seu acompanhamento.

A Rotina das aulas é outro aspecto considerado fundamental para o Programa Circuito Campeão e deve constar no planejamento do professor. A rotina escolar é uma sequência de atividades que visam à organização do tempo que o aluno permanece na escola. Apoia-se na reprodução diária de momentos e nos indícios e sinais que remetem às situações do cotidiano. Embora não haja referências do IAS sobre a rotina, destacamos que dela fazem parte as seguintes etapas que o professor deve seguir: Acolhida, Correção da lição de casa, Formação de hábitos de leitura, Desenvolvimento da aula, Revisão do dia e a Lição de casa. Todos os dias, os professores devem seguir esses passos ao elaborarem suas aulas.

A sistemática de planejamento do professor está delineada pelas ações que o Circuito Campeão estabelece, ou seja, o docente vai planejar conforme o que já está definido e estabelecido nas matrizes de habilidades. Se o planejamento pressupõe antecipar ações para determinados fins e objetivos, no programa, o planejamento do professor praticamente está pronto, restando-lhe organizar as atividades conforme as matrizes dadas.

Na Figura 1 apresenta-se o esquema desenvolvido pelo Programa Circuito Campeão para organização do planejamento pelo professor. Conforme apresentado 
nessa figura, o objetivo do planejamento é chegar às metas estabelecidas pelo programa. O professor atinge as metas cumprindo as matrizes de habilidades, organizando os fluxos das aulas, acompanhando a leitura e a escrita dos alunos, através dos resultados das avaliações e dos indicadores do programa.

Figura 1 - Planejamento no Programa Circuito Campeão

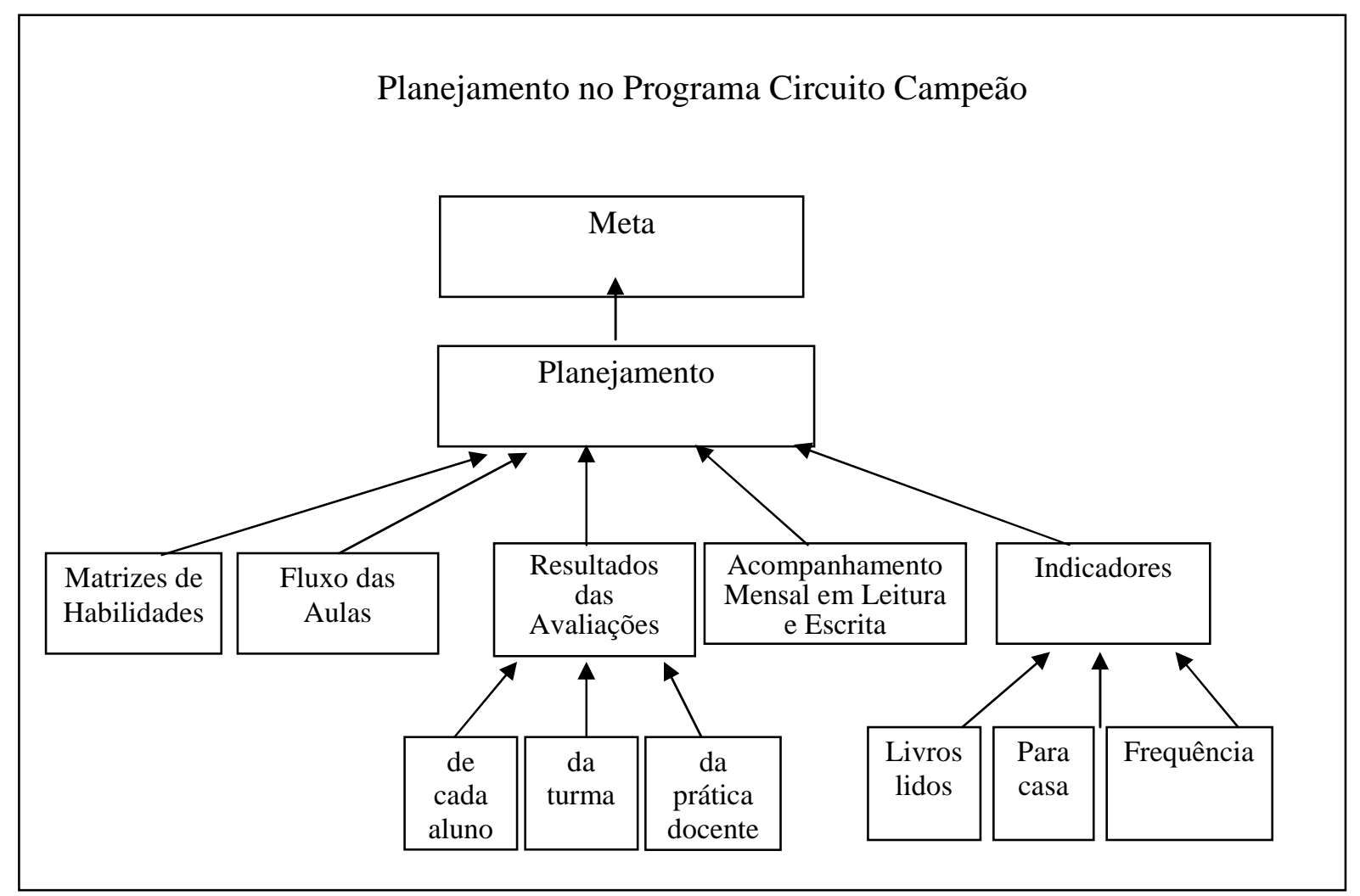

Fonte: Capacitação do Programa Circuito Campeão, 2009.

Com base no "pressuposto da neutralidade científica e inspirada nos princípios da racionalidade, eficiência e produtividade" (SAVIANI, 2010, p. 381), a aproximação do planejamento do Programa Circuito Campeão tem como proposta torná-lo objetivo e operacional É impressionante a aproximação do processo de planejamento desse programa com a pedagogia tecnicista, haja vista que a operacionalização dos objetivos e a mecanização do processo de planejamento estão contempladas na proposta, através da padronização de esquemas de planejamento previamente formulados, aos quais se devem ajustar as disciplinas e práticas pedagógicas. Lembra-nos Saviani (2010, p. 382) que, nessa pedagogia, "o elemento principal passa a ser a organização racional dos meios, sendo professor e 
aluno posição secundária, relegados à condição de meros executores do processo de planejamento".

Sobre o planejamento do trabalho escolar do Programa Circuito Campeão, encontramos também outra abordagem, que parte do pressuposto de que os conteúdos escolares constituem-se em ferramentas para propiciar o desenvolvimento de competências/habilidades em crianças e jovens. Isso implica uma organização específica da prática pedagógica do professor, da sala de aula, da formação de grupos de alunos e dos materiais utilizados (Material da Capacitação Inicial, 2009).

No programa em questão, a opção pelo trabalho com matriz de competências e habilidades ocorre tanto no processo coletivo do planejamento quanto no individual do professor. Essa contradição apresentada em relação ao planejamento é alvo de nossa análise. Verificamos que o processo de planejamento apresenta duas abordagens: uma totalmente tecnicista e gerencial, e outra, conforme Duarte (2001), voltada às pedagogias do aprender a aprender, termo apropriado pelas reformas educacionais atuais.

Para Duarte,

[...] tal movimento ganha força justamente no interior do aguçamento do processo de mundialização do capital e de difusão, na América Latina, do modelo econômico, político e ideológico neoliberal[...]. É nesse quadro de luta intensa do capitalismo, por sua perpetuação, que o lema aprender a aprender é apresentando como a palavra de ordem que caracterizaria uma educação democrática (DUARTE, 2001, p. 30-31).

Buscando explicitar o "aprender a aprender" (DUARTE, 2001; SAVIANI, 2010; DELORS, 1998), é que, a partir de meados da década de 1980, diante da profunda recessão econômica e do aumento nas pressões competitivas internacionais, decorrentes da nova crise estrutural, o capitalismo busca novos mecanismos de recomposição também na educação. Assim, o lema "aprender a aprender" desempenha um importante papel na adequação do discurso pedagógico contemporâneo às necessidades do processo de mundialização do capital, pela vinculação ao discurso político-econômico neoliberal. É no interior das chamadas teorias construtivistas que se desloca a questão do ensino para a aprendizagem, tão referenciada pelo Relatório Delors (1998), base da fundamentação teórica do IAS. 
Já o modelo de planejamento do Programa Circuito Campeão assinala as competências finais a serem adquiridas pelos alunos, deixando margem de flexibilidade para que o professor e a escola definam os conteúdos. Ou seja, o conteúdo a ser ministrado pode ficar a critério das escolas, contanto que as competências finais sejam atingidas pelos alunos. Portanto, temos um discurso de autonomia, mas, na prática, o controle é intensificado.

A avaliação como integrante do currículo escolar, mais do que um instrumento, é um processo permanente do trabalho docente, tendo como propósito observar se o aluno aprendeu ou não, podendo, assim, refletir sobre o nível de qualidade do trabalho escolar, tanto do aluno quanto do professor, gerando mudanças significativas na prática escolar. Porém, a concepção de avaliação que predomina é a de manutenção da avaliação como forma de classificação, por meio de provas e notas, ou seja, a avaliação de produto, mesmo que, muitas vezes, o ônus pelo fracasso seja debitado exclusivamente ao aluno (HOFFMAN, 2009).

A avaliação do aluno no Circuito Campeão se aproxima muito com o exposto anteriormente, pois parte do diagnóstico, a partir das Matrizes de Habilidades, visando orientar a tomada de decisão das equipes, a partir dos resultados. Quanto aos objetivos específicos das avaliações, apresenta, conforme Capacitação dos Professores (2009): restabelecer o compromisso com o sucesso de todos os alunos; diagnosticar entraves na aprendizagem; estimular um processo reflexivo e de autocrítica por todos os profissionais envolvidos, a partir dos resultados; direcionar o replanejamento durante o processo; provocar a melhoria da gestão do ensino e da aprendizagem dos alunos; ampliar a compreensão dos professores acerca das habilidades das matrizes.

O instrumento utilizado para avaliar é, principalmente, a prova, cujo objetivo é a avaliação dos conhecimentos e habilidades dos alunos a partir de uma amostra dos temas desenvolvidos em aula - Matriz de Habilidades - e tem como modelo a avaliação do aluno, que é baseada nos acertos e erros dos itens da prova, conhecida como Teoria de Resposta ao Item ${ }^{3}$. Após, é feito um escore do aluno, que

\footnotetext{
${ }^{3}$ A Teoria da Resposta ao Item (TRI), metodologia de avaliação usada pelo Ministério da Educação no Exame Nacional do Ensino Médio (ENEM), não contabiliza apenas o número total de acertos no teste. De acordo com o método, o item é a unidade básica de análise. O desempenho em um teste pode ser explicado pela habilidade do avaliado e pelas características das questões (itens). A TRI qualifica o item de acordo com três parâmetros: poder de discriminação, que é a capacidade de um
} 
corresponde ao número de itens respondidos de forma correta pelo aluno, e seu desempenho é determinado pelo número de itens que ele respondeu corretamente na prova.

A avaliação tem como foco, principalmente, o resultado. É importante frisar que todos os documentos que abordam os programas do instituto destacam essa questão dos resultados. Goldenberg (2008, p. 20), em entrevista à Revista Educação em Cena, afirma que "assim como os processos utilizados no segundo setor, as ações educacionais do Instituto foram estruturadas com a mesma lógica empresarial, criando estratégias focadas em resultados". Lembra que, no caso dos programas educacionais do Instituto, há planos de ação e metas a serem atingidas, com o objetivo de se alcançarem resultados.

Os resultados aparecem no programa Circuito Campeão traduzidos por metas, indicadores e percentuais, tendo em vista que todas as ações devem, necessariamente, ser guiadas por indicadores e metas e, consequentemente, por resultados a serem alcançados. A gestão dos resultados é um dos focos principais do programa, pois as três avaliações realizadas ao longo do ano, além das avaliações do professor, buscam incessantemente o alcance dos resultados estipulados pelo programa. Além disso, a escola presta conta dos resultados ao IAS através do SIASI- Sistema Ayrton Senna de Informações. Se considerarmos a gestão gerencial, o controle é exercido em "toda a vida do produto ou serviço, e não apenas na concepção e produção, mas inclui todas as atividades administrativas e de gestão".

Novamente, a gestão gerencial é exemplificada na versão de Xavier (1996), quando os resultados estão associados a todos os envolvidos: cada um no seu nível deve ter objetivos, identificar problemas e adotar medidas preventivas e corretivas. Para ele, todos devem estar em um mesmo movimento, desde as autoridades até quem executa o programa.

Paro (2011, p. 709) alerta que a avaliação por provas e exames torna-se um indicador insuficiente da qualidade da educação, principalmente quando são 0

item distinguir os estudantes que têm a proficiência requisitada daqueles quem não a têm; grau de dificuldade; possibilidade de acerto ao acaso (chute). Essas características permitem estimar a habilidade de um candidato avaliado e de garantir que essas habilidades, medidas a partir de um conjunto de itens, sejam comparadas com outro conjunto na mesma escala, ainda que eles não sejam os mesmos e que haja quantidades diferentes de itens usados para o cálculo. 
balizador de um sistema de ensino. O objetivo da escola deixa de ser educar e formar cidadãos e passa a ser obter alta pontuação nas avaliações externas. Para isso, a instituição escolar implementa projetos com o objetivo de "treinar" os alunos a responderem corretamente aos testes. Dessa forma, o que acaba pautando a educação escolar não é o objetivo de construir personalidades, mas de formar pessoas que respondam adequadamente a essas provas (PARO, 2011).

A avaliação é uma atividade que envolve legitimidade técnica e legitimidade política na sua realização. O avaliador, seja ele o professor, o coordenador ou o diretor, deve realizar a tarefa com a legitimidade técnica que sua formação profissional the confere. Entretanto, o professor deve estabelecer e respeitar princípios e critérios refletidos coletivamente, referenciados no projeto políticopedagógico, na proposta curricular e em suas convicções acerca do papel social que desempenha a educação escolar. Esse é o lado da legitimação política do processo de avaliação e que envolve também o coletivo da escola.

Para Fernandes e Freitas,

se a escola é o lugar da construção da autonomia e da cidadania, a avaliação dos processos, sejam eles das aprendizagens, da dinâmica escolar ou da própria instituição, não deve ficar sob a responsabilidade apenas de um ou de outro profissional, é uma responsabilidade tanto da coletividade, como de cada um, em particular (2007, p. 17).

Nessa lógica apresentada pelo Circuito Campeão, o ensino está divorciado da aprendizagem. O sucesso ou o fracasso do aluno passa a ser equacionado a partir das suas possibilidades individuais, constituídas a partir de seu esforço e de sua adequação ao modelo imposto a ele. Tal modelo é construído a partir da lógica mercadológica emprestada da gestão empresarial: relação custo/benefício, empreendedorismo, eficiência/eficácia, competências e habilidades. Essa lógica transforma o cidadão político em cidadão-cliente.

As concepções anteriores que apresentamos integram o currículo escolar e têm como princípio norteador, no Programa Circuito Campeão, o desenvolvimento do potencial de todas as crianças e jovens, por meio do aprimoramento das competências pessoais, sociais, profissionais e cognitivas. Para traduzir esse princípio em práticas pedagógicas que compõem o currículo, os programas do IAS subsidiam a educação formal com propostas curriculares organizadas em matrizes de competências e habilidades. 
Problematizando o que parece ser fundamental no programa, o IAS utiliza o currículo pautado no princípio dos quatro pilares da Educação para o século XXI, do relatório da Unesco, organizado por Jacques Delors. O IAS transforma o trabalho de Delors em quatro competências para o desenvolvimento de potenciais, praticadas no dia a dia dos programas e projetos. São elas o aprender a ser (a capacidade de ser você mesmo e construir o seu projeto de vida); o aprender a conviver (com as diferenças e com o meio em que vive, cultivando novas formas de participação social); o aprender a fazer (atuando produtivamente para ingressar e permanecer no novo mundo do trabalho); e o aprender a conhecer (apropriando-se dos próprios instrumentos de conhecimento e colocando-os a serviço do bem comum).

Nesse sentido, vários pesquisadores vêm evidenciando os reais objetivos dos currículos pautados em competências, que são a base das reformas educacionais em nível mundial. Ressaltam-se, nesse grupo, Jacomelli (2008) e Ramos (2001). Jacomelli (2008) afirma que as reformas educacionais que ocorreram por todo o mundo, inclusive no Brasil, trazem os mesmos princípios educacionais. Isso referenda a afirmação de que há um projeto de sociedade sendo pensado e engendrado pelos ideólogos que defendem o capitalismo. Para Jacomelli (2008), nesse projeto, a educação escolar é pensada como a melhor ferramenta para conformar espíritos, incutir valores, homogeneizar discursos e fazer com que os indivíduos aceitem como natural a reestruturação do capitalismo, com suas diferenças econômicas, sociais, culturais e outras.

Partindo do mito da igualdade de oportunidades para todos, através da educação, o documento da Unesco, também utilizado como base para os programas do IAS, retoma e atualiza ideias através do "conceito de educação ao longo de toda a vida de modo a conciliar a competição que estimula a cooperação e a solidariedade que une" (JACOMELLI, 2008, p. 165). Para a autora, a educação, ao longo de toda a vida, torna-se, assim, o meio de chegar a um equilíbrio mais perfeito entre trabalho e aprendizagem, bem como ao exercício de uma cidadania ativa.

Para Marise Ramos (2001, p. 130), "descarta-se a educação para a cidadania em favor da educação para a produtividade, uma educação baseada em procedimentos". Para a autora, se a escola historicamente era vista como uma promessa de emprego, agora passa a ser vista como um caminho para a empregabilidade sob a responsabilidade de cada um. Ou seja, o que antes seria um 
projeto de sociedade, passa a ser encarado como um projeto de indivíduos moldáveis, adaptáveis. Em resumo, esse cenário possibilita o surgimento de uma nova ética.

Já Arroyo (2007) questiona o currículo que vem conformando os sujeitos da ação educativa - docentes e alunos - uma vez que esse conforma suas vidas, produz identidades escolares: quem será o aluno bem sucedido? O fracassado, 0 aprovado, o reprovado, o lento, o desacelerado, o especial? Ser reconhecido como escolarizado ou não? Em que nível condiciona até o direito ao trabalho?. Para o teórico, durante o percurso escolar, aprendemos a ser alunos como a escola quer ou como espera que sejamos. "A escola fará tudo para que aprendamos a ser o protótipo de alunos que ela deseja. O molde para conformá-los é o ordenamento curricular" (ARROYO, 2007, p. 22).

Pelo exposto, podemos afirmar que o currículo, alicerçado nos pressupostos do Programa Circuito Campeão, conforme já apresentado, vê os alunos como recursos humanos a serem formados para o mercado de trabalho. Seremos levados a privilegiar e selecionar as habilidades e competências, segundo a mesma lógica segmentada, hierarquizada e seletiva. "O currículo organizado por lógicas de mérito e sucesso nada mais é do que a tradução curricular da lógica do mercado e da visão mercantilizada que nós fazemos dos educandos" (ARROYO, 2007, p. 18).

Enquanto isso, os professores, como sujeitos do trabalho docente, ficam à mercê das habilidades que o mercado impõe aos futuros trabalhadores. Nessa proposta de privilegiar a docência quanto às exigências do mercado, "os horizontes profissionais se fecham, perdemos a autoria, estreitamos o leque de autoescolhas, renunciamos à possibilidade de ter outro projeto de sociedade, de formação humana, de educação. Vendemos nossa realização profissional ao mercado" (ARROYO, 2007, p. 26).

\section{Considerações finais}

Se pensarmos o homem como objetivo da educação e sua condição de sujeito histórico e social, ele faz história ao produzir cultura (PARO, 2011, p. 25). Para isso, ele precisa apropriar-se da cultura historicamente produzida, e a escola é 
- lugar em que esse saber sistematizado pode contribuir para a emancipação humana, com um projeto próprio.

O projeto político-pedagógico é a própria organização do trabalho pedagógico da escola, gerando uma nova organização, que reduz os efeitos da divisão do trabalho, da fragmentação e do controle hierárquico. Exige a reflexão da concepção de educação e de homem a ser formado, sendo a própria escola que explicita os fundamentos teórico-metodológicos, objetivos, conteúdos, metodologias, organização e formas de avaliação da instituição, garantidos pela LDB (Lei de Diretrizes e Bases) nos artigos 13 e 14.

Contraditoriamente, a proposta do Programa Circuito Campeão, ao ser implantado nas escolas, desconsidera os processos e os sujeitos, ao apontar que sua proposta pode ser aplicada independente da concepção de educação e método de trabalho, sendo uma proposta padronizada para todas as escolas do Brasil, ao mesmo tempo em que os docentes são excluídos do processo e da construção da gestão democrática. Isso fica evidente quando, tanto no planejamento quanto na avaliação, tudo já está delineado e organizado pelo próprio programa. Outra contradição na aplicação do Programa Circuito Campeão é o esvaziamento do conteúdo pedagógico, pois o processo de gerenciamento aniquila o conteúdo pedagógico relacionado ao ensino e aprendizagem, tornando-o um processo mecanizado, baseando a aula em um produto pronto e organizado através de manual, conforme o padrão da empresa, desconsiderando o espaço em que está inserido o discente.

$\mathrm{Na}$ tentativa de responder à pergunta presente no título deste artigo, a educação no sentido de apropriação do saber historicamente construído não condiz com um ensino fragmentado, que se preocupa apenas com a lógica do mercado e com a ideia de profissionalização. Nesse modelo de educação, as questões políticas e participativas do cidadão acabam ficando em segundo plano, ou, simplesmente, extintas na discussão educacional.

Ao implantar os programas do IAS, os sistemas e as escolas vêm abdicando de seu papel de preparar o ser humano como cidadão para atuar democraticamente em sociedade, considerando, para além dos conteúdos, o desenvolvimento de valores necessários para a convivência democrática. Esse é o pedagógico que não encontramos na concepção educativa do IAS. 


\section{Referências}

ARROYO, Miguel Gonzáles. Indagações sobre currículo, educandos e educadores: seus direitos e o currículo. Brasília: Ministério da Educação, Secretaria de Educação Básica, 2007.

CURY, Carlos R. Jamil. Educação e contradição. São Paulo: Cortez: Autores Associados. 1992.

DELORS, Jacques (Org). Educação: um tesouro a descobrir. São Paulo: Cortez/Brasília: MEC; UNESCO, 1998.

DUARTE, Newton. Vigotski e o "aprender a aprender": críticas às apropriações neoliberais e pós-modernas da teoria vigotskiana. Campinas: Autores Associados, 2001.

EVANGELISTA, Olinda. Formação docente no Brasil e interesses internacionais. 2007. Disponível em: <www.gepeto.ced.ufsc.br>. Acesso em: 10 abr. 2010.

FERNANDES, Cláudia de Oliveira; FREITAS, Luiz Carlos de. Indagações sobre Currículo: Currículo e avaliação. Brasília: Ministério da Educação, Secretaria de Educação Básica, 2007.

GOLDENBERG. Margareth. Avaliação continua Instituto Ayrton Senna. Revista Educação em Cena, São Paulo, n. 3., p. 20., 2008.

INSTITUTO AYRTON SENNA. Circuito Campeão. Disponível em: <http://senna.globo.com/institutoayrtonsenna/novo_site/programas/programas_circuit ocampeao.asp>. Acesso em: 5 mar. 2010.

JACOMELLI, M. R. M. Parâmetros curriculares nacionais (PCNS) para o ensino fundamental e Relatório Delors: estabelecendo aproximações. Quaestio (UNISO), v. 10, p. 145-172, 2008.

LIBÂNEO, José Carlos. Pedagogia e pedagogos, para quê? 6. ed. São Paulo: Cortez, 2002.

MACHADO, Lucília Regina. Transformações tecnológicas e padrão de qualificação. Educação em Revista, Belo Horizonte, n. 14, 1994.

MISKALO. Inês Kisil. Soluções Educacionais para o Desenvolvimento Humano. Educação: teoria e prática, v. 19, n. 32, jan./jun. 2009, p. 37-55.

MALINI, Eduardo. O consenso como ponto de partida? Uma análise dos papéis desempenhados pelos atores participantes na formulação do plano de desenvolvimento da educação. Dissertação (Mestrado) - Universidade Federal de Juiz de Fora, Juiz de Fora, 2009. Disponível em:

<www.ufjf.br/ppge/files/2010/07/Eduardo-Maline.pdf>. Acesso em: 20 jan. 2012. 
PARO, Vitor Henrique. Escritos sobre educação. São Paulo: Xamã, 2002.

. Progressão continuada, supervisão escolar e avaliação externa:

implicações para a qualidade do ensino. Rev. Bras. Educ. [online], v. 16, n. 48, p. 695-716, 2011.

RAMOS, M. N. Dicionário da Educação Profissional em Saúde, 2009. Pedagogia das Competências. Disponível em:

<http://www.epsjv.fiocruz.br/dicionario/verbetes/pedcom.html>. Acesso em: 31 ago. 2012.

SAVIANI, D. História das idéias pedagógicas no Brasil. Campinas: Autores Associados, 2010.

VEIGA, IIma Passos A. Projeto político-pedagógico da escola: uma construção coletiva In: (Org.). Campinas: Papirus, 2004.

VEIGA, IIma Passos A.; RESENDE, Lucia Maria Gonçalves de (Orgs). Escola: espaço do projeto político pedagógico. Campinas: Papirus, 1996.

XAVIER, Antonio Carlos da R. A gestão da qualidade e a excelência dos serviços educacionais: custos e benefícios de sua implantação. Texto para discussão, n. 408. Brasília: IPEA, 1996. 